\title{
Balance and Single Line to Ground Fault Location in Electrical Distribution System
}

\author{
Misagh Alaie Faradonbeh, Student Member, IEEE, Hazlie Bin Mokhlis, Member, IEEE, Mazaher \\ Karimi, Student Member, IEEE, Amidaddin Shahariari, Student Member, IEEE
}

\begin{abstract}
This paper outlines impedance based technique and its application for determining the location of a fault on a distribution system. A few well-know fault location methods are first discussed and analyzed to highlight its practicality as compared to impedance based technique. The practicality of the impedance based technique in locating a fault is shown by testing it on a Canadian distribution network. The algorithm of the impedance based technique is developed and integrated into PSCAD/EMTDC software by using C-interface and FORTRAN Language. Various test cases showed the practicality of the impedance based technique in locating a fault.
\end{abstract}

Index Terms-Fault Location, Balanced Fault, Distribution Network, Single Line to Ground Fault

\section{INTRODUCTION}

E lectric power systems have grown rapidly over the past fifty years. This has resulted in a large increase of the number of lines in operation and their total length. These lines experience faults which are caused by storms, lightning, snow, freezing rain, insulation breakdown and short circuits caused by birds and other external objects. In most cases, electrical faults manifest in mechanical damage, which must be repaired before returning the line to service.

Various fault location techniques have been developed to assist power system engineers in locating fault fast. By detecting fault fast, the correct faulted section could be isolated and therefore minimize restoration time. The restoration can be expedited if the location of the fault is either known or can be estimated with reasonable accuracy. Fault locators provide estimate for both sustained and transient faults. Generally, transient faults cause damage that is not easily visible on inspection. Fault locators help identify those locations for early repairs to prevent recurrence and consequent major damages. Furthermore, accurate fault location can also assists the utility personnel to identify where faults regularly occur and preventive measures could be taken [1-7].

In the past, fault location techniques have been developed mainly for transmission system. This due to the fact that transmission network is a backbone of the whole power system. Any disturbance in the system may affect huge area and cause high losses. However with the deregulated environment and high competition between companies, a fast fault location for distribution system has been also a great interest of many utilities. Thus, various techniques have been

misagh_alaie@siswa.um.edu.my

hazli@um.edu.my

Mazaher@siswa.um.edu.my

shahriariamid@siswa.um.edu.my proposed [9-15]. These techniques are using different types of measurement to locate fault.

With the growing interest in power quality, power quality monitors that capture power quality phenomena have become an important tool. Hence, measurements of voltages and currents before and during the fault are easily available and possible to be used to locate the origin of the fault. Considering the availability of the power quality data from measurement, this paper presents the impedance based technique to locate fault using voltage and current data from measurement. This paper also discuss various well-known methods to high light the advantages and disadvantages.

\section{OVERVIEWS OF FAULt LocATION Methods}

In general, fault location methods can be classified into two categories; two measurement and single measurement. In the following, some well-known methods for finding fault location on AC distribution systems are described. The studied methods are as follows:

- Takagi algorithm [11].

- Reactive component method $[9,10]$.

- Richards and Tan algorithm [12].

- Srinivasan and St-Jacques algorithm [13].

- Girgis algorithm [14].

- Impedance based method part of Das method $[6,15]$.

The impedance based method is using voltage and current to finds the apparent reactance from the terminal measurement to the place of fault. The method can calculate the fault distance in kilometers or miles based on the apparent reactance [15]. Another impedance method proposed by Stan and Paithankar [8,9] is estimating the fault location by measuring the steady state fundamental frequency voltage and current at one terminal of lines. Then it is possible to calculating the apparent impedance from this data. The basic principle of the method is illustrated in Fig.1.

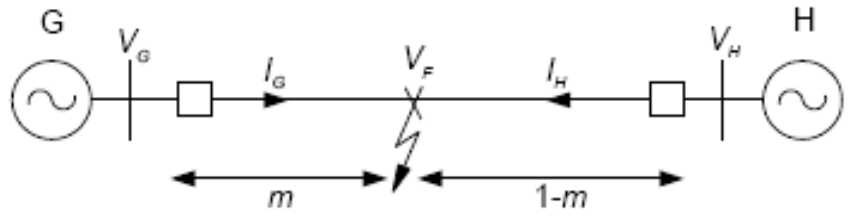




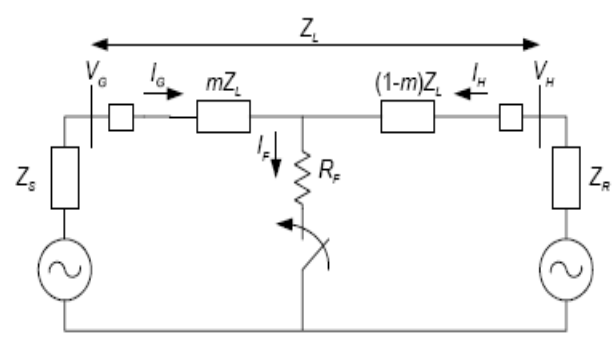

Fig.1. Analysis three phase faults

In this part some parameters will be defined and trying to find apparent impedance when the fault is appeared [1].

$V_{G}$ is the voltage at terminal $G$.

$M \quad$ is the distance to the fault in per unit.

$Z_{L}$ is the line impedance between terminals $G$ and $H$.

$I_{G} \quad$ is the line current from terminal $G$.

$R_{F}$ is the fault resistance.

$I_{F} \quad$ is the total fault current.

Using of KVL method for the circuit during the fault and the equation is:

$\mathrm{V}_{\mathrm{G}}=\mathrm{mZ}_{\mathrm{L}} \mathrm{I}_{\mathrm{G}}+\mathrm{R}_{\mathrm{F}} \mathrm{I}_{\mathrm{F}}$

So, in this part for finding equal Impedance Just necessary to dividing voltage to the current and the equation is:

$\mathrm{Z}_{\mathrm{FG}}=\frac{\mathrm{V}_{\mathrm{G}}}{\mathrm{I}_{\mathrm{G}}}=\mathrm{mZ}_{\mathrm{L}}+\mathrm{R}_{\mathrm{F}} \frac{\mathrm{I}_{\mathrm{F}}}{\mathrm{I}_{\mathrm{G}}}$

$Z_{F G}$ is the apparent impedance to the fault measured at terminal $G$.

The Takagi method just can estimate the single phase to ground fault in Electrical power system models. If other kinds of faults appear the result of fault location has large error. Srinivasan and St-Jacques method use the simple Model of network for real network and all kind of fault. This method can estimate the place of fault but it is so expensive and it is not economical because the instruments of collecting data are expensive. The Girgis method has some limitations for finding the location of fault as following. The network for analyzing this method is a simple network. An electrical power distribution system has parallel and lateral loads. Testing system just includes single phase fault, not all kind of the fault. The impedance based method is the best practical and economical method.

\section{TEST NETWORK}

Saskpower $25 \mathrm{KV}$ network of Sask State in Canada is modeled in PSCAD/EMTDC. Single phase diagram is shown in Fig.2 as follows [15].

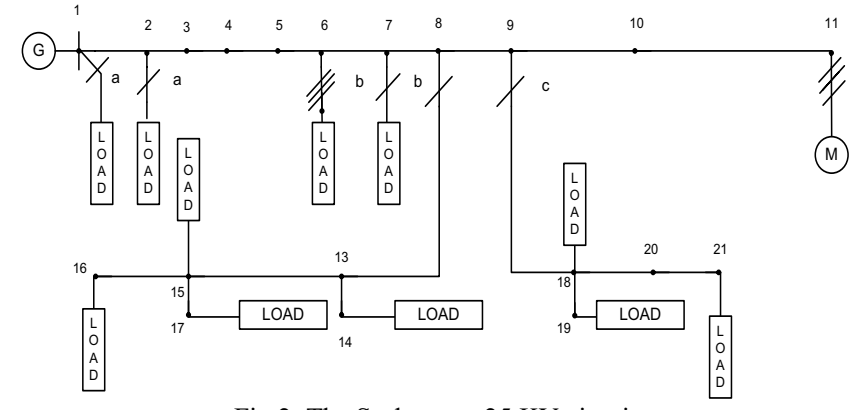

Fig.2. The Saskpower $25 \mathrm{KV}$ circuit
Impedance based method just needs one measurement for finding the location of fault. This measurement is installed at first feeder of distribution system or after generator for distribution system to measure the value of current, voltage, active and reactive power.

The network has 21 sections; these lines are different in impedance value that is shown in Table I.

TABLE I

VALUE OF DIFFERENT LINES FOR NEW COMPONENTS (SERIES IMPEDANCE)

\begin{tabular}{c|c|cc}
\hline Section & \multirow{2}{*}{$\begin{array}{c}\text { Length Of } \\
\text { Noden }\end{array}$} & \multicolumn{2}{|c}{ Series Impedance $($ Ohms $/$ Km $)$} \\
\cline { 3 - 4 } Section $($ Km $)$ & Zero Sequence & Positive Sequence \\
\hline $1 \& 2$ & 2.414 & $0.5254+\mathrm{j} 1.704$ & $0.3480+\mathrm{j} 0.5166$ \\
$2 \& 6$ & 16.092 & $0.5254+\mathrm{j} 1.704$ & $0.3480+\mathrm{j} 0.5166$ \\
$6 \& 7$ & 4.023 & $0.5254+\mathrm{j} 1.704$ & $0.3480+\mathrm{j} 0.5166$ \\
$7 \& 8$ & 5.150 & $0.7290+\mathrm{j} 1.727$ & $0.5519+\mathrm{j} 0.5390$ \\
$8 \& 9$ & 2.414 & $0.7290+\mathrm{j} 1.727$ & $0.5519+\mathrm{j} 0.5390$ \\
$9 \& 10$ & 4.506 & $0.7290+\mathrm{j} 1.727$ & $0.5519+\mathrm{j} 0.5390$ \\
$10 \& 11$ & 2.414 & $0.5254+\mathrm{j} 1.704$ & $0.3480+\mathrm{j} 0.5166$ \\
$6 \& 12$ & 2.414 & $0.5254+\mathrm{j} 1.704$ & $0.3480+\mathrm{j} 0.5166$ \\
$8 \& 13$ & 2.414 & $7.3977+\mathrm{j} 0.8998$ & $7.3977+\mathrm{j} 0.8998$ \\
$13 \& 14$ & 2.414 & $7.3977+\mathrm{j} 0.8998$ & $7.3977+\mathrm{j} 0.8998$ \\
$13 \& 15$ & 2.414 & $7.3977+\mathrm{j} 0.8998$ & $7.3977+\mathrm{j} 0.8998$ \\
$15 \& 16$ & 2.414 & $7.3977+\mathrm{j} 0.8998$ & $7.3977+\mathrm{j} 0.8998$ \\
$15 \& 17$ & 2.414 & $7.3977+\mathrm{j} 0.8998$ & $7.3977+\mathrm{j} 0.8998$ \\
$9 \& 18$ & 2.414 & $7.3977+\mathrm{j} 0.8998$ & $7.3977+\mathrm{j} 0.8998$ \\
$18 \& 19$ & 2.414 & $7.3977+\mathrm{j} 0.8998$ & $7.3977+\mathrm{j} 0.8998$ \\
$18 \& 20$ & 3.219 & $7.3977+\mathrm{j} 0.8998$ & $7.3977+\mathrm{j} 0.8998$ \\
$20 \& 21$ & 3.219 & $7.3977+\mathrm{j} 0.8998$ & $7.3977+\mathrm{j} 0.8998$ \\
\hline
\end{tabular}

\section{Positive Sequence Calculation for Balance Fault}

Three phases to ground fault is simulated at different nodes on Saskpower distribution system in the PSCAD $\ E M T D C$ software. The purpose of this part is to analyze the value of apparent sequence impedance for each kind of fault for different sections. In this simulation, Fault is simulated at 0.2 second until 0.7 second. The measurement data which are voltage, current, active and reactive power are taken at 0.45 second and the taken data are shown in Table II. For example: The output wave form the network node 2 that is simulated in PSCAD/EMTDC software such as; current and voltage and active and reactive power are shown in Fig.3 and Fig.4 for single line to ground fault.

TABLE II

VALUE OF DIFFERENT DATA OF MEASUREMENT IN SASKPOWER DISTRIBUTION SYSTEM FOR BALANCE FAULT

\begin{tabular}{|c|c|c|c|c|c|}
\hline \multirow[b]{2}{*}{ Data } & \multirow{2}{*}{ Section } & \multicolumn{4}{|c|}{ Three phase to ground fault } \\
\hline & & Node 2 & Node 6 & Node 8 & Node11 \\
\hline \multirow{5}{*}{$\begin{array}{c}\text { Phase } \\
\text { A } \\
\text { B } \\
\& \\
\text { C }\end{array}$} & $\mathrm{V}(\mathrm{KV})$ & 3.81 & 10.5 & 11.32 & 11.83 \\
\hline & $\mathrm{I}(\mathrm{KA})$ & 2.48 & 0.90 & 0.63 & 0.48 \\
\hline & $\mathrm{P}(\mathrm{KW})$ & 5.06 & 5.40 & 4.40 & 3.62 \\
\hline & $\mathrm{Q}(\mathrm{KVAR})$ & 8.36 & 8.50 & 6.22 & 4.77 \\
\hline & $\theta$ (Degree) & 56.18 & 57.57 & 54.72 & 52.80 \\
\hline
\end{tabular}




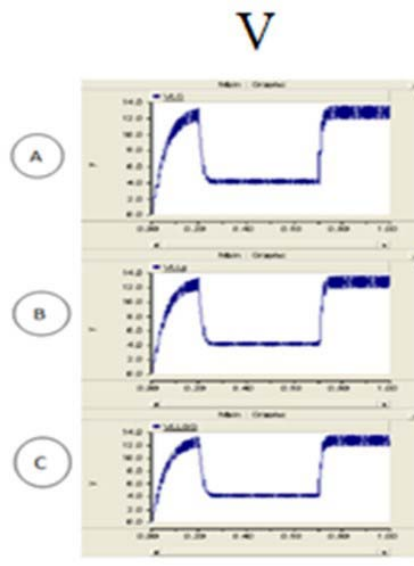

(a)

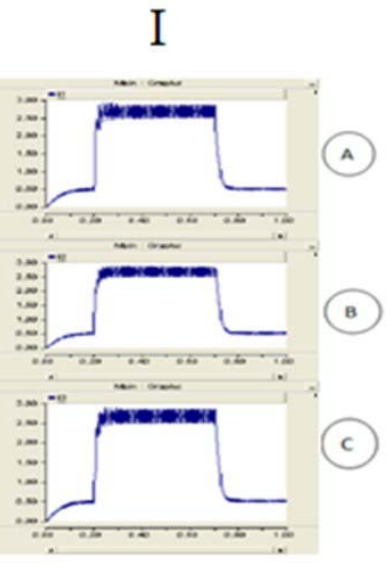

(b)
Fig.3. (a) Voltage wave form of voltage in each phase during the single line to ground fault and (b) Current wave form of voltage in phase during the single phase to ground fault

Finding the value of apparent impedance for Positive sequence during the three phase to ground fault. The positive sequence can be calculated using measured data. The calculation is described as follows, for calculation of phase angle (angle between current and voltage).

$\tan ^{-1} \frac{Q_{(a, b, c)}}{P_{(a, b, c)}}=\theta_{(a, b, c)}$

Where:

$P_{a}, P_{b}$ and $P_{c}$ is active power of phase A, phase B and Phase C, respectively. $Q_{a}, Q_{b}$ and $Q_{c}$ is reactive power of phase A, phase $\mathrm{B}$ and Phase $\mathrm{C}$ respectively.
In balance fault the output values of measurement (voltage and current) are positive values. Therefore, the value of positive apparent impedance can be reach with formula that shows a follow:

$Z_{\text {apparent } \text {,positive }}=\frac{V[0]}{I \text { [0] }}$

The final results for finding the apparent impedance for each nod are described as follows:

$>$ Three phase to ground Faults at node 2:

$[\mathrm{Za}]=[\mathrm{Zb}]=[\mathrm{Zc}]=\frac{[\mathrm{Va}]}{[\mathrm{Ia}]}=[0.85520-j 1.27661]$

$>$ Three phase to ground Faults at node 6:

$[\mathrm{Za}]=[\mathrm{Zb}]=[\mathrm{Zc}]=\frac{[\mathrm{Va}]}{[\mathrm{Ia}]}=[6.356-j 9.9318]$

$>$ Three phase to ground Faults at node 8:

$[\mathrm{Za}]=[\mathrm{Zb}]=[\mathrm{Zc}]=\frac{[\mathrm{Va}]}{[\mathrm{Ia}]}=[10.45-j 14.81]$

$>$ Three phase to ground Faults at node 11:

$[\mathrm{Za}]=[\mathrm{Zb}]=[\mathrm{Zc}]=\frac{[\mathrm{Va}]}{[\mathrm{Ia}]}=[15.014-j 19.6735]$

Thus, when three phase fault appears at different sections to approach the absolute value of impedance's reactance part at (node $2=1.27661$, node $6=9.9318$, node $8=14.81$, node $11=19.6735$ ) are increased as distance of fault.

Comparing between positive sequence's reactance part of line impedance and positive sequence's reactance part of apparent impedance during fault during fault is shown in Fig.5.

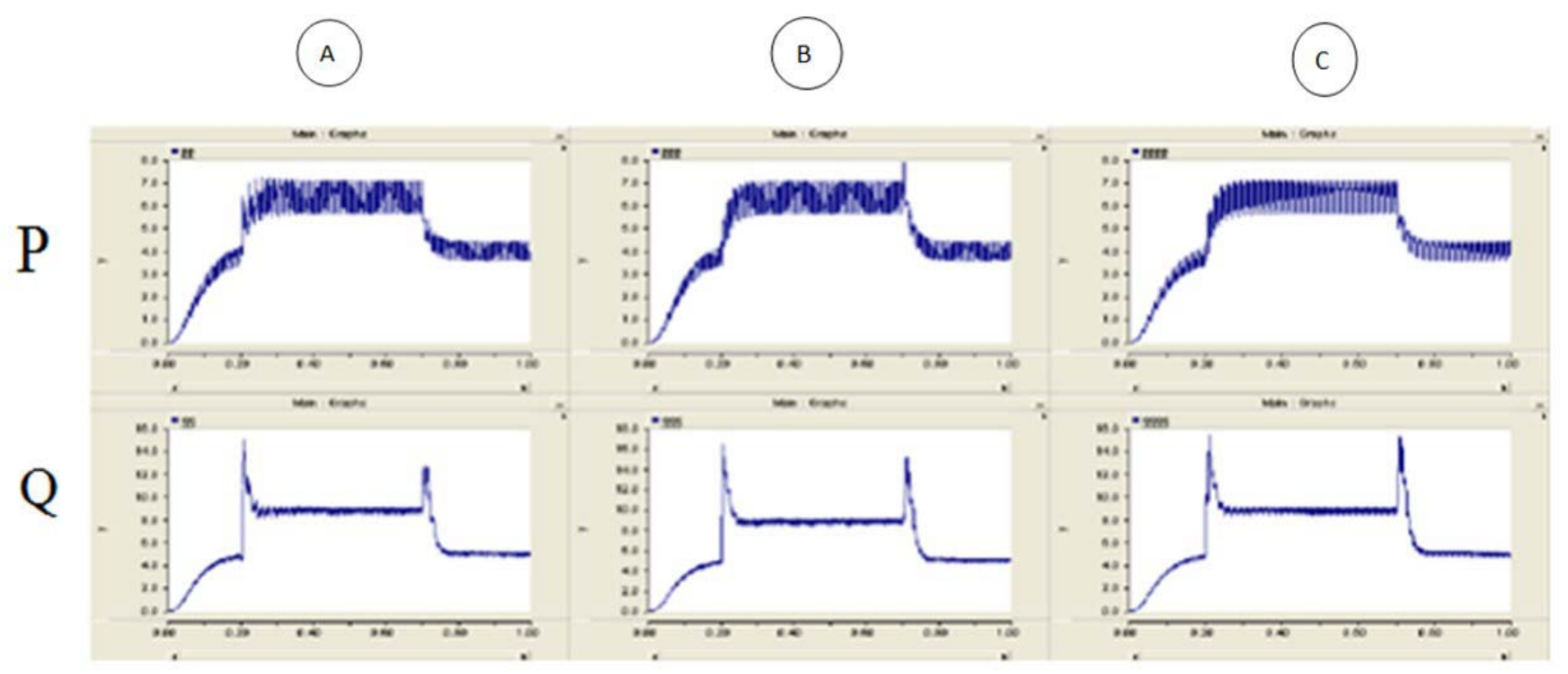

Fig.4. Above figure is shown Active power and next figure is shown reactive power for each phase 


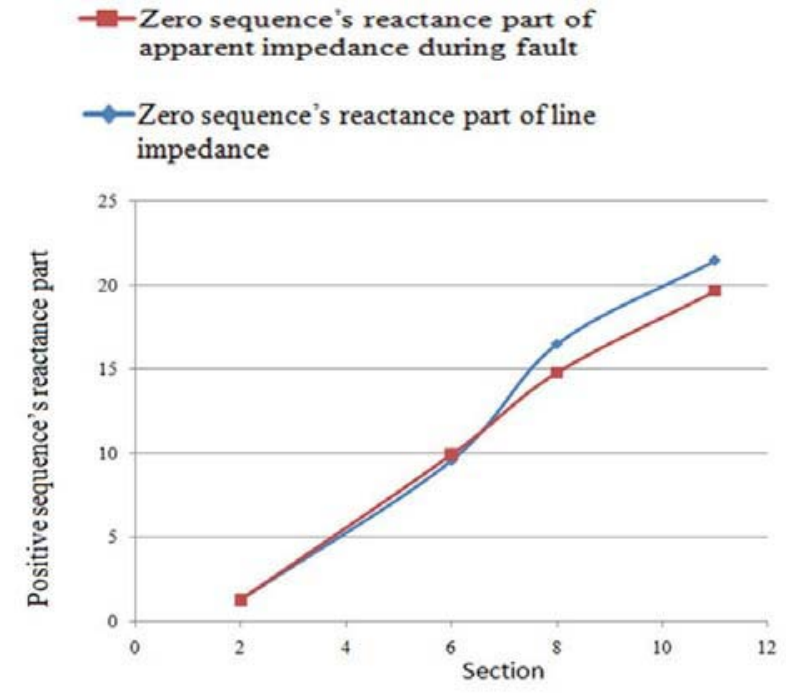

Fig.5. Comparation of line impedance and apparent impedance during fault Single phase to ground

\section{ZERo SEQUENCE IMPEDANCE CALCULATION}

The zero sequence can be calculated using measured data. The calculation is described as follows, for calculation of phase angle (angle between current and voltage).

$\tan ^{-1} \frac{\mathrm{Q}_{(\mathrm{a}, \mathrm{b}, \mathrm{c})}}{\mathrm{P}_{(\mathrm{a}, \mathrm{b}, \mathrm{c})}}=\theta_{(\mathrm{a}, \mathrm{b}, \mathrm{c})}$

Where:

$P_{a}, P_{b}$ and $P_{c}$ is active power of phase A, phase B and Phase C respectively. $Q_{a}, Q_{b}$ and $Q_{c}$ is reactive power of phase A, phase $\mathrm{B}$ and Phase $\mathrm{C}$ respectively.

To calculate the value of sequence voltage of current and voltage, the following equations are used:

$$
\begin{aligned}
& {\left[\begin{array}{l}
V_{a}^{(0)} \\
V_{a}^{(1)} \\
V_{a}^{(2)}
\end{array}\right]=\frac{1}{3}\left[\begin{array}{ccc}
1 & 1 & 1 \\
1 & a & a^{2} \\
1 & a^{2} & a
\end{array}\right]\left[\begin{array}{l}
V_{a}<0^{o} \\
V_{b}<0^{0} \\
V_{c}<0^{0}
\end{array}\right]} \\
& {\left[\begin{array}{c}
I_{a}^{(0)} \\
I_{a}^{(1)} \\
I_{a}^{(2)}
\end{array}\right]=\frac{1}{3}\left[\begin{array}{ccc}
1 & 1 & 1 \\
1 & a & a^{2} \\
1 & a^{2} & a
\end{array}\right]\left[\begin{array}{l}
I_{a}<\theta_{a}^{0} \\
I_{b}<\theta_{b}^{0} \\
I_{c}<\theta_{c}^{0}
\end{array}\right]}
\end{aligned}
$$

Where:

$V_{a} \quad$ is voltage of phase A during the fault.

$V_{b}$ is voltage of phase B during the fault.

$V_{c} \quad$ is voltage of phase $\mathrm{C}$ during the fault.

$I_{a} \quad$ is current of phase A during the fault.

$I_{b} \quad$ is current of phase B during the fault.

$I_{c} \quad$ is current of phase $\mathrm{C}$ during the fault.

$$
\mathrm{a}=1<120^{0}, a^{2}=1<240^{0}, a^{3}=1<360^{\circ}
$$

Sequence of apparent impedance:

$$
\left[\begin{array}{c}
Z_{a}^{(0)} \\
Z_{a}^{(1)} \\
Z_{a}^{(2)}
\end{array}\right]=\frac{\left[\begin{array}{c}
V_{a}^{(0)} \\
V_{a}^{(1)} \\
V_{a}^{(2)}
\end{array}\right]}{\left[\begin{array}{l}
I_{a}^{(0)} \\
I_{a}^{(1)} \\
I_{a}^{(2)}
\end{array}\right]}
$$

In this simulation, fault is simulated when the value of impedance sequence is calculated. Value of apparent impedance sequence should be analyzed with different faulted section on ac distribution system. A general equation to calculate the sequence impedance can be program using Matlab program.

\section{OutPut Data of Measurement (During Fault)}

Single line to ground fault is simulated at different nodes on Saskpower distribution system in the PSCAD $\$ EMTDC software. The purpose of this part is to analyze the value of apparent sequence impedance for each kind of fault for different sections, in this simulation.

Fault is simulated at 0.2 second until 0.7 second. The measurement data which are voltage, current, active and reactive power are taken at 0.45 second and the taken data are shown in Table III. For example: The output wave form of the network that is simulated in PSCAD/EMTDC software such as; current and voltage and active and reactive power are shown in Fig.3 and Fig.4 for single line to ground fault.

\begin{tabular}{|c|c|c|c|c|c|}
\hline \multirow[b]{2}{*}{ Data } & \multirow{2}{*}{ Section } & \multicolumn{4}{|c|}{ Single Line to ground fault } \\
\hline & & Node 2 & Node 6 & Node 8 & Node11 \\
\hline \multirow{5}{*}{$\begin{array}{c}\text { Phase } \\
\text { A }\end{array}$} & $\mathrm{V}(\mathrm{KV})$ & 6.40 & 11.00 & 11.55 & 11.85 \\
\hline & $\mathrm{I}(\mathrm{KA})$ & 2.73 & 0.77 & 0.55 & 0.47 \\
\hline & $\mathrm{P}(\mathrm{KW})$ & 7.60 & 5.00 & 4.26 & 3.60 \\
\hline & $\mathrm{Q}(\mathrm{KVAR})$ & 17.00 & 7.66 & 5.25 & 4.75 \\
\hline & $\theta$ (Degree) & 65.91 & 56.86 & 50.94 & 52.48 \\
\hline \multirow{5}{*}{$\begin{array}{c}\text { Phase } \\
\text { B }\end{array}$} & $\mathrm{V}(\mathrm{KV})$ & 11.60 & 11.80 & 11.75 & 11.85 \\
\hline & $\mathrm{I}(\mathrm{KA})$ & 0.52 & 0.55 & 0.53 & 0.47 \\
\hline & $\mathrm{P}(\mathrm{KW})$ & 3.76 & 7.66 & 4.40 & 3.64 \\
\hline & $\mathrm{Q}(\mathrm{KVAR})$ & 5.00 & 5.60 & 4.84 & 4.72 \\
\hline & $\theta$ (Degree) & 53.05 & 54.46 & 47.72 & 52.36 \\
\hline \multirow{5}{*}{$\begin{array}{c}\text { Phase } \\
\text { C }\end{array}$} & $\mathrm{V}(\mathrm{KV})$ & 10.00 & 11.50 & 11.80 & 11.85 \\
\hline & $\mathrm{I}(\mathrm{KA})$ & 0.73 & 0.44 & 0.41 & 0.47 \\
\hline & $\mathrm{P}(\mathrm{KW})$ & 3.76 & 3.90 & 3.44 & 3.59 \\
\hline & $\mathrm{Q}(\mathrm{KVAR})$ & 2.92 & 3.50 & 3.77 & 4.66 \\
\hline & $\theta$ (Degree) & 47.99 & 41.90 & 47.62 & 53.39 \\
\hline
\end{tabular}
TABLE III

VALUE OF DifFerent DATA OF MEASUREMENT IN SASKPOWER DISTRIBUTION SYSTEM

VII. ANALYSIS OF APPARENT IMPEDANCE VALUE Apparent impedance for different kind of unblance faults and different sections on Saskpower distribution system During fault was calculated as follows.

Single phase to ground at nodes $2,6,8$ and when fault appears at node 2 .

$$
\left[\begin{array}{l}
Z_{a}^{(0)} \\
Z_{a}^{(1)} \\
Z_{a}^{(2)}
\end{array}\right]=\frac{\left[\begin{array}{c}
V_{a}^{(0)} \\
V_{a}^{(1)} \\
V_{a}^{(2)}
\end{array}\right]}{\left[\begin{array}{l}
I_{a}^{(0)} \\
I_{a}^{(1)} \\
I_{a}^{(2)}
\end{array}\right]}=\left[\begin{array}{c}
3.6300-6.9319 i \\
-0.0144+1.9858 i \\
-1.3452+1.4902 i
\end{array}\right]
$$

When fault appears at node 6 and 8 :

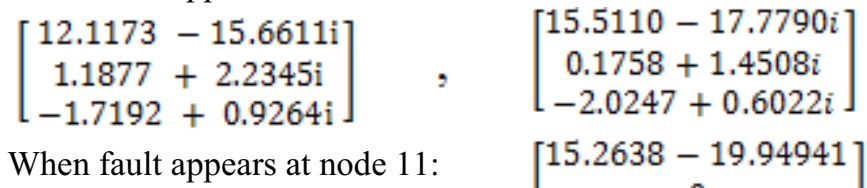




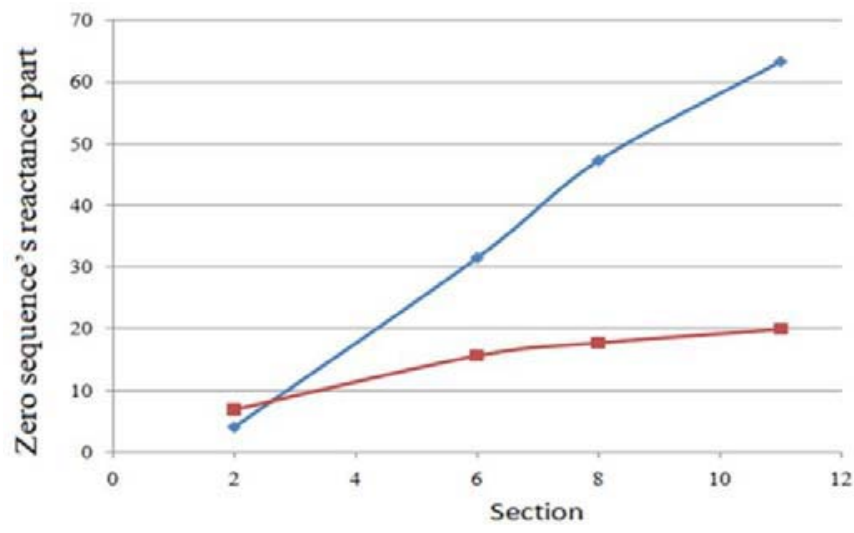

Fig.6. Comparation of line impedance and apparent impedance during fault single phase to ground

It can be seen that when single phase to ground fault occurred at different sections to approach the absolute value of zero impedance sequence's reactance part at (node $2=6.9319$, node $6=15.6611$, node $8=17.779$ and node $11=19.94941)$ are increased as distance of fault increasing.

Comparing between zero sequence's reactance part of line impedance and zero sequence's reactance part of apparent impedance during fault is shown in Fig.6.

\section{CONCLUSION}

From the comparison of these methods, it was found that the impedance based method is most practical and economical implication. The correlation between fault distances and apparent impedance are studied. This is presented in last chapter, whereby the graphs show that as the fault distance increases the sequence apparent reactance is also increasing. The method has been tested using balance and single line to ground faults, this method finds the location of fault by analyzing the Positive and Zero sequence's reactance part value.

\section{REFERENCES}

"IEEE Guide for Determining Fault Location on AC Transmission and Distribution Lines," IEEE Std C37.114-2004, pp. 0_1-36, 2005.

[3] J. Mora-Florez, et al., "Learning-based strategy for reducing the multiple estimation problem of fault zone location in radial power Systems," Generation, Transmission \& Distribution, IET, vol. 3, pp. 346-356, 2009.

[4] N. Tleis, Power systems modelling and fault analysis: theory and practice: Newnes, 2008.

[5] T. Short, Electric power distribution equipment and systems: CRC press, 2006.

[6] G. Morales-Espana, et al., "Elimination of Multiple Estimation for Fault Location in Radial Power Systems by Using Fundamental Single-End Measurements," Power Delivery, IEEE Transactions on, vol. 24, pp. 1382-1389, 2009.

[7] W. D. S. John J.Grainger, Power system analysis, 1994

[8] G. Swift and D. Fedirchuk, "Arcing Fault 'Resistance'(it isn't)," 2002, pp. 22-24.

[9] Y. Paithankar and M. Sant, "A new algorithm for relaying and fault location based on autocorrelation of travelling waves," Electric Power Systems Research, vol. 8, pp. 179-185, 1985.

[10] D. Novosel, et al., "Unsynchronized two-terminal fault location estimation," Power Delivery, IEEE Transactions on, vol. 11, pp. 130-138, 2002.
[11] T. Takagi, et al., "Development of a new type fault locator using the one-terminal voltage and current data," power apparatus and systems, ieee transactions on, pp. 2892-2898, 2007.

[14] A. Girgis, et al., "A fault location technique for rural distribution feeders," Industry Applications, IEEE Transactions on, vol. 29, pp. 1170-1175, 2002.

[15] R. Das, et al., "A fault locator for radial sub transmission and distribution lines," 2002, pp. 443-448.

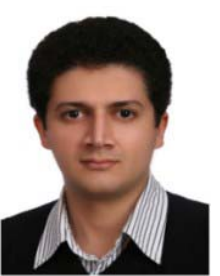

Misagh Alaie Faradonbeh recived his B.Eng.degree in 2005 from Azad university of IRAN Najafabad branch, and M.Sc. degree in 2010 from Malaya university. His research interest is Electrical power system (Transmission and Distribution) Power quality, stability, EMC \& Islanding. stability, EMC \& Islanding.

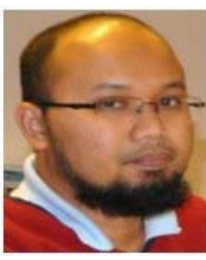

Hazlie Bin Mokhlis recived his M.Sc. degree from Malaya university, and Ph.D degree in 2009 from Manchester University, United Kingdom. His research interest is Electrical power system (Transmission and Distribution) Power quality, stability, EMC \& Islanding.

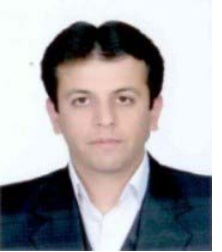

Mazaher Karimi received his Bachelor degree from Azad university of IRAN, and currently he is master student in University of Malaya. His research interest is power system stability and Distributed Generation.

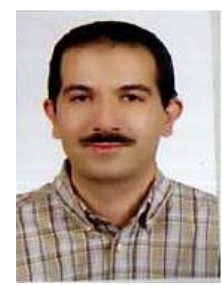

Amidaddin Shahriari received his B. Eng in Electrical Engineering from Tehran Azad University and M. Eng. from Iran University of Science Technology. He is $\mathrm{PhD}$ student in University of Malaya. His main research interest is in numerical analysis of power system performance. 